\title{
ISOLATED IDIOPATHIC UNILATERAL PARALYSIS OF SOFT PALATE: A CASE REPORT
}

Ruchi Verma1, Vidya $\mathrm{H}^{2}$

\section{HOW TO CITE THIS ARTICLE:}

Ruchi Verma, Vidya H. "Isolated Idiopathic Unilateral Paralysis of Soft Palate: A Case Report". Journal of Evolution of Medical and Dental Sciences 2015; Vol. 4, Issue 30, April 13; Page: 5234-5236,

DOI: $10.14260 /$ jemds/2015/765

ABSTRACT: Isolated unilateral palatal (Velopalatopharyngeal) palsy is a clinical rarity. We report this entity in a 12 year old boy. The child was managed with a short course of prednisolone with complete recovery in ten days.

KEYWORDS: Palatal paralysis, Rhinolalia clausa.

INTRODUCTION: Idiopathic unilateral palatal paralysis is a rare disorder. It was first described in 1976. ${ }^{1}$ The disorder typically affects boys at ages of 2-18 years with sudden onset rhinolalia clausa and nasal regurgitation of fluids. ${ }^{2-5}$ We report a 12 year old boy with this illness who recovered completely.

CASE REPORT: 12 year old male child presented to the OPD with history of sudden change in voice since 1 day, associated with regurgitation of fluids through the right nostril and difficulty in swallowing since then. There was no history of any febrile illness prior to the symptoms. Child was immunized up to date.

On examination, oral cavity was normal. There was deviation of uvula to right [Figure 1] and absence of gag reflex over right side and regurgitation of fluids through the right nostril was evident during swallowing [Figure 2]. Rest of the neurological examination and laryngoscopy was normal.

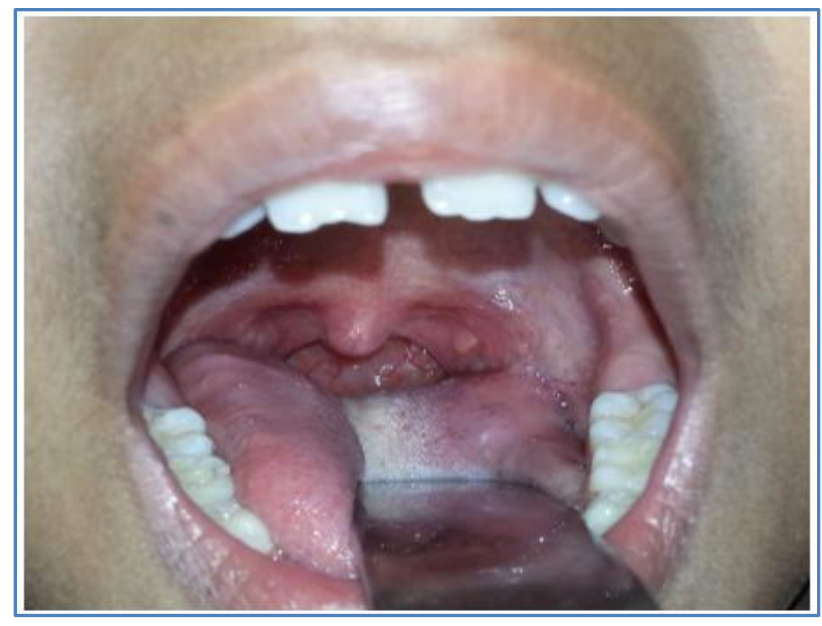

Fig. 1: Shows Deviation of Uvula to right

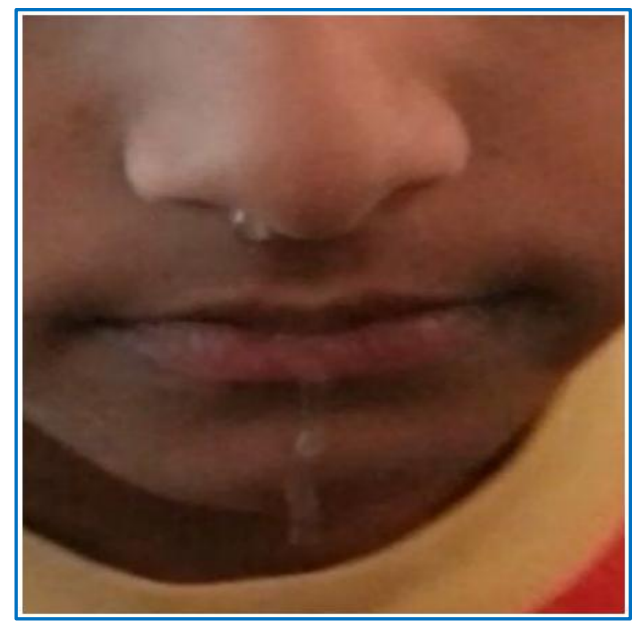

Fig. 2: Shows regurgitation of fluid from right nostril during swallowing 
The child was started on oral prednisolone $(1 \mathrm{mg} / \mathrm{kg} /$ day). Steroids were tapered from 5 th day and stopped on day 15. The symptoms started improving on day four of steroids and the child was completely asymptomatic ten days after starting steroids. The palatal palsy recovered completely by tenth day from the onset of symptoms.

DISCUSSION: We consider that vagus is the most probable nerve affected. The mode of involvement of vagus is not known but two mechanisms have been hypothesized: viral and vascular. ${ }^{5}$ An infectious/ post infectious cranial neuropathy seems likely as isolated palatopharyngeal palsy is well documented a post diphtheritic complication. The clinical features of diphtheria were not present in our patient and also, he was completely vaccinated. There have been sporadic reports of palatopharyngeal palsy in children following infection with herpes, varicella and hepatitis A. ${ }^{3}$ However, definitive evidence in the form of positive viral serology / culture could be demonstrated in only five of the twelve cases with a febrile prodrome. ${ }^{3,5}$

The second hypothesis has been proposed by Lapresle et al.6 They demonstrated the existence of ischemia in the roots of the glossopharyngeal and vagus nerves. The cause of this ischemia is not known and viral infection induced vasculitis cannot be ruled out. Either of the fore mentioned scenarios would lead to lower motor neuron neuropathy manifesting as palatopharyngeal incompetence. The higher incidence of the condition in childhood is possibly due to immature neural tissue that is rendered more susceptible than in adults.

Other possibilities considered were Guillain-Barre syndrome, vascular insults, posterior fossa tumors, syringobulbia and inflammatory diseases affecting brainstem nuclei. Detailed pharyngeal and neurologic examination and MRI of the brain and upper cervical region were unremarkable. We consider the paralysis in our case to be idiopathic because all the evaluations were negative.

The prognosis of the disorder is excellent with complete recovery in $>85 \%$ cases $^{5}$ and only one recurrence reported till date. There is no specific treatment; oral glycerol and steroids have been used and complete recovery has been reported even without any treatment. ${ }^{3}$ We managed the case with short course of steroids without any side effects and the child started improving from day four and the recovery was complete by day eleven. Several reports suggest initiation of recovery by tenth day and reversal of pharyngeal weakness by 4-7 weeks without the use of steroids. ${ }^{3,5}$ Nonetheless, further reports focusing on the therapeutic aspect are desired, before a recommendation is made.

\section{REFERENCES:}

1. Edin $\mathrm{M}$, Sveger $\mathrm{T}$, Tegner $\mathrm{H}$, Tjernstrom O. Isolated temporary pharyngeal paralysis in childhood. Lancet. 1976; 1: 1047-9.

2. Villarejo-Galende A, Camacho-Salas A, Penas-Prado M, Garcia-Ramos R, Mendoza MC, Simon de las Heras R, et al. Unilateral isolated paralysis of the soft palate: a case report and a review of the literature. Rev Neurol. 2003; 36: 337-9.

3. Prasad PL, Prasad AN, Patnaik SK. Unilateral palatal palsy with viral hepatitis. Indian J Pediatr. 2007; 74: 1039-40.

4. Cuvellier JC, Cuisset JM, Nuyts JP, Vallee L. Acquired and isolated asymmetrical palatal palsy. Neuropediatrics. 1998; 29: 324-5.

5. Alp H, Tan H, Altunkaynak S, Orbak Z. Idiopathic unilateral paralysis of the palate in childhood. Pediatr Neurol. 2005; 33: 134-5. 


\section{CASE REPORT}

6. Lapresle J, Lasjaunias P, Thevenier D. Transitory paralysis of cranial nerves IX, X and XII as well as the left VII after angiography. Contribution to the ischemic pathology of the cranial nerves. Rev Neurol. 1980; 136: 787-91.

\section{AUTHORS: \\ 1. Ruchi Verma \\ 2. Vidya $H$.}

\section{PARTICULARS OF CONTRIBUTORS:}

1. Assistant Professor, Department of ENT, Dr. B. R. Ambedkar Medical College, Bangalore.

2. Junior Resident, Department of ENT, Dr. B. R. Ambedkar Medical College, Bangalore.

\section{FINANCIAL OR OTHER} COMPETING INTERESTS: None

\section{NAME ADDRESS EMAIL ID OF THE CORRESPONDING AUTHOR:}

Dr. Ruchi Verma,

C115, Raheja Residency, $3^{\text {rd }}$ Block, Koramangala,

Bangalore-560034.

E-mail: ruchiutkarsh@gmail.com

Date of Submission: 17/03/2015.

Date of Peer Review: 18/03/2015.

Date of Acceptance: 31/03/2015.

Date of Publishing: 13/04/2015. 